\title{
Health Risk Assessment Associated With Bisphenol A (A Case Study of Qatar)
}

كلية الآداب والعلوم

College of Arts and Sciences

جATAR UNIVERSITY جامعة
Suraj Adewale BELLO

Department of Biological and Environmental Sciences, College of Arts and Sciences, Qatar University

\section{Abstract}

This study aimed to evaluate exposure to bisphenol A in drinkable water. Much study has not been conducted on Bisphenol A in the drinkable water globally, Arabia gulf particularly in Qatar. This assessment studies the probable risks associated with exposure of children as well as adults to bisphenol A in drinkable water around Doha. The risk assessment was conducted based on the water analyses collected over the two seasons (winter and summer) as well as most recent bisphenol A toxicity data published (US EPA) Environmental Protection Agency, USA. It was found that the concentration levels of bisphenol A $(0.0002205 \mathrm{mg} / \mathrm{kg}$ b.w./day, $0.0001515 \mathrm{mg} / \mathrm{kg}$ b.w./day) in both seasons fell below acceptable levels $(0.05 \mathrm{mg} / \mathrm{kg}$ b.w./day). Statistical analysis established that there is no variation in the concentration levels during summer and winter. The calculated health risk assessment which were hazard quotient or hazard ratio and hazard index were less than one (summer 6.18E-02 < 1, winter 14.24E-02 < 1). Hence, noncarcinogenic health risk were found to be within the safety limit for bisphenol. Keywords: Bisphenol, risk, dose, hazard.

\section{Introduction}

ore than 800,000 substances precisely chemicals with various properties are in use all across the globe and nearly 1000 - 2000 newly produced chemicals enter the market annually, but unfortunately Environmental Protection or Management Agencies(EPA) fail to take regular routine check to assess the associated risks and safety common with the existing or newly introduced chemicals. Bisphenol A (BPA) has been categorized among the large group of organic contaminant that are just emerging lately. It is partially hydroxylated hydrophobic ring carbon attached with methyl functional groups as well as one or more functional groups with methyl functional groups as well as one or more functional groups with
hydrophilic properties which enhances its solubility when in contact with hydrophilic properties which enhances its solubility when in contact with
water. BPA consider to be of great threat to the environment recently established from numerous studies. BPA leaches often from the baby bottles made from polycarbonate (Vandenberg et al. 2007a) as well as reusable bottles used in water bottling factories as well as reusable bottles used in water bottling factories (Le et al. 2008). BPA was suspected to be hela consunable produch liver disease, oncological diseases, diabetes, obesity, dermatitis, irritation of mucous membranes of the eyes.

\section{Objectives}

1. To identify possible source of BPA in drinkable water.

2. To conduct health risk assessment of BPA in drinkable water through ingestion route

\section{Methodology-}

\section{Methods 1 - Does - Response}

\section{Animals}

Male and female DBA/1J mice, $8-9$ weeks of age, were used in the experiments.

\section{Administration of BPA}

Varying doses $\left(3,30,300\right.$, and $\left.3000 \mu \mathrm{g} \mathrm{kg}^{-1}\right)$ of BPA (Sigma) were given orally for 20 days.

\section{Method 2 - Sampling and sample preparation}

Samples of drinkable water were collected around Doha, and out of the total samples collected, only nine samples with their replicates were used for this study. Adequate chemical analyzed was assumed to have been carried out to determine their respective concentrations as shown in the table (supplementary)

Method 3 - Potential health risk assessment model

\section{$A D D=(C(\mathrm{mg} / \mathrm{mL}) * \mathbb{R}(\mathrm{mL} / \mathrm{kg}$-day) $*$ EF (days/year) $*$ ED (years) $) /(\mathrm{AT}$} (days)

\section{Risk characterization}

The non-carcinogenic health risk whenever applicable to any human being exposure is a way of expressing the toxicity level of a pollutant bisphenol $\mathrm{A}$ in water, is a dimensionless quantity known as hazard quotient (HQ). The risk of exposure to BPA is determined from the equation:

\section{$\mathrm{HQ}=\frac{\mathrm{ADD}}{\mathrm{RfD}} \quad \sum_{i=1}^{n} \mathrm{HI}=\sum_{i=1}^{n} \frac{\mathbf{A D D}_{i}}{\mathbf{R f D}_{\mathrm{i}}}$}

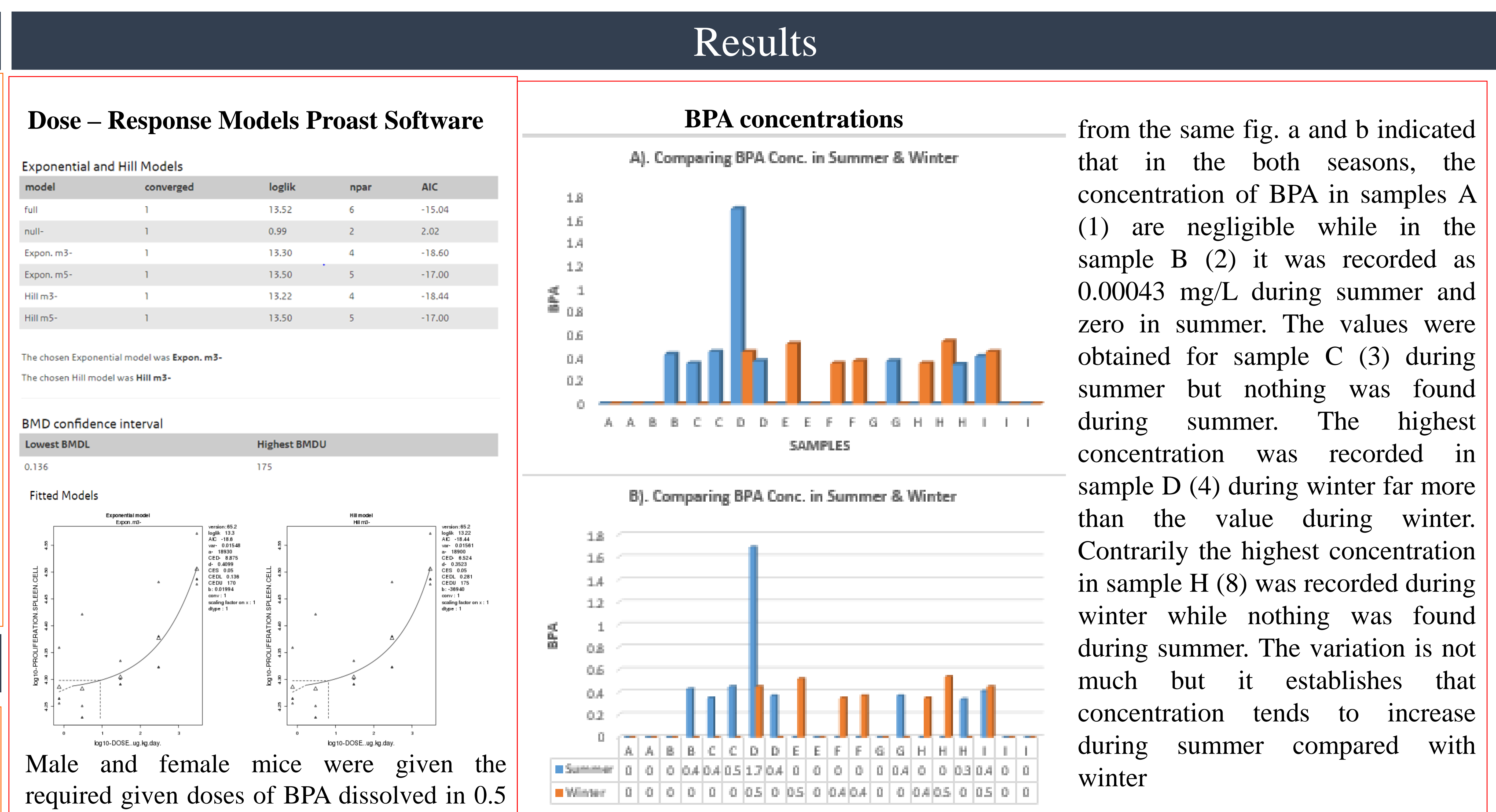

Statistical analysis

of HEL. Both sexes exposed to BPA showed increased in all the responses examined. The increases in rates of proliferation spleen cell increases as the dose increases. From the graph it clearly shown that as dose increases, proliferation of spleen ceil increases, a positive dose response to BPA. It was considered that there were no differences in this responses between males and females as they exhibited $73 \%$ and $56 \%$ response rate. Summarily, there is positive relationship between the dose(s) of BPA and corresponding response proliferation of spleen cell

\begin{tabular}{|c|c|c|}
\hline \multicolumn{3}{|c|}{ Health Risk Assessment } \\
\hline & Summer & Winter \\
\hline \multirow{2}{*}{$\mathbf{H Q}=\frac{\mathbf{A D D}}{\mathbf{R A D}}$} & $0.0618=6.18 \mathrm{E}-02$ & $0.0424=4.24 \mathrm{E}-02$ \\
\hline & $<1$ & $<1$ \\
\hline$\sum_{i=1}^{n} \mathbf{H I}=\sum_{i=1}^{n} \frac{\mathbf{A D D}_{\mathbf{i}}}{\mathbf{R f D}_{\mathbf{i}}}$ & & \\
\hline
\end{tabular}

The average daily dose (ADD) of BPA from water samples around Doha for people of all age based on our assumption through the majorly known
We actually hypothesized that "seasonal variation will have effect on the concentration levels of BPA". However it was found not to be significant at 0.05 (significant level) because the calculated $\mathrm{P}$ - value is 0.785 (Table 6) which is greater than 0.05 . So, the season have no control on the quantity of BPA that can be release into water at any particular time all thing being equal
Mixed Model statistical analysis that involved the type III Tests of Fixed Effects was performed on the BPA to find out if the is variation in the concentration levels of BPA is enhanced by the two seasons; winter and summer.

\begin{abstract}
exposure pathway (route) ingestion was calculated using equation (1) or (2) but as shown in the table $3 a$ and $b$ it was generated from the Expo FIRST software for the both seasons; summer and winter. The maximum ADD was recorded for the population investigated with the 3.09E-03 during the summer season and 2.21E-03 during the winter season.

Also, the health risk levels were estimated from the HQ for exposure route (ingestion) with non-carcinogenic health risk index (HI) for all age group calculated by using the equations (3) and (5). From HQ obtained for both seasons, they were less than 1; for summer $0.0618=6.18 \mathrm{E}-02<1$ and winter $0.0424<1=4.24 \mathrm{E}-02$ (Table 5) and cumulatively, HI $=\mathbf{0 . 0 1 0 4 2}<\mathbf{1}($ Eqn. 6). Hence there is probability of non-carcinogenetic effect through the exposure route investigated. In a plain language, the drinkable water around Doha is safe of consumption as the level of BPA cannot possibly cause any carcinogenic threat in the all age habiting or living around the city of Doha.
\end{abstract}

\section{Conclusions}

Nine samples of drinkable water with replicates were randomly collected in the city of Doha, Qatar were carefully investigated for their BPA concentrations.

Concentration levels of BPA based on the seasonal variation, varies with concentration levels during summer season greater than that of winter but statistically insignificant.

Non-carcinogenic risk estimated for all age group through exposure route for both seasons were found to lie within acceptable safety levels.

There is no any potential risk that can cause cancer through drinking water.

From the study, the estimated health risks were far below the level that might cause concern.

\section{References}

Le Hoa H.et.al. 2008. "Bisphenol A Is Released from Polycarbonate Drinking Bottles and Mimics the Neurotoxic Actions of Estrogen in Developing Cerebellar Neurons." Toxicology Letters 176 (2) Elsevier:

https://doi.org/10.1016/J.TOXLET.2007.11.001 $49-56$

Tarja LAANINEN. 2018. "New Rules on Bisphenol A in Food Contact Materials - Think Tank." At a Glance. 2018. https://doi.org/NIL.

US EPA, ORD, Integrated Risk Information System Division. 2013. "Bisphenol A. CASRN 80-05-7 | IRIS US EPA, ORD." Accessed October 19, 2018. https://cfpub.epa.gov/ncea/iris2/chemicalLanding.cfm?s ubstance nmbr $=356$ 